\title{
Ten-year audit of clients presenting to a specialised service for young people experiencing or at increased risk for psychosis
}

\author{
Agatha M Conrad ${ }^{1 *}$, Terry J Lewin ${ }^{1,2}$, Ketrina A Sly ${ }^{1}$, Ulrich Schall ${ }^{1,2,4}$, Sean A Halpin ${ }^{1,4,5}$, Mick Hunter ${ }^{5}$ \\ and Vaughan J Carr ${ }^{2,3}$
}

\begin{abstract}
Background: Despite strong research interest in psychosis risk identification and the potential for early intervention, few papers have sought to document the implementation and evaluation of specialised psychosis related services. Assessment of Ultra High Risk (UHR) has been given priority, but it is equally as important to identify appropriate comparison groups and other baseline differences. This largely descriptive service evaluation paper focuses on the 'baseline characteristics' of referred clients (i.e., previously assessed characteristics or those identified within the first two months following service presentation).
\end{abstract}

Methods: Data are reported from a 10-year layered service audit of all presentations to a 'Psychological Assistance Service' for young people (PAS, Newcastle, Australia). Baseline socio-demographic and clinical characteristics $(N=1,997)$ are described (including clients' psychosis and UHR status, previous service contacts, hospitalisation rates, and diagnostic and comorbidity profiles). Key groups are identified and comparisons made between clients who received ongoing treatment and those who were primarily assessed and referred elsewhere.

Results: Clients averaged 19.2 (SD =4.5) years of age and 59\% were male. One-tenth of clients (9.6\%) were categorised as UHR, among whom there were relatively high rates of attenuated psychotic symptoms (69.1\%), comorbid depression (62.3\%), anxiety (42.9\%), and attentional and related problems (67.5\%). Overall, one-fifth (19.8\%) experienced a recent psychotic episode, while a further $14.5 \%$ were categorised as having an existing psychosis ( $46.7 \%$ with a schizophrenia diagnosis), amongst whom there were relatively high rates of comorbid substance misuse (52.9\%), psychosocial (70.2\%) and physical health (37.7\%) problems. The largest group presenting to PAS were those with non-psychotic disorders (43.7\%), who provide a valuable comparison group against which to contrast the health trajectories of those with UHR and recent psychosis. Ongoing treatment by PAS was preferentially given to those experiencing or at risk for psychosis and those reporting greater current distress or dysfunction.

Conclusions: Whether or not UHR clients transition to psychosis, they displayed high rates of comorbid depression and anxiety at service presentation, with half receiving ongoing treatment from PAS. Although international comparisons with similar services are difficult, the socio-demographic and comorbidity patterns observed here were viewed as largely consistent with those reported elsewhere.

Keywords: Psychosis, Risk status, Service evaluation, Comorbidity, Youth, Early intervention

\footnotetext{
* Correspondence: Agatha.Conrad@hnehealth.nsw.gov.au

'CTNMH (MH-READ), Hunter New England Mental Health and the University of Newcastle, McAuley Centre, The Mater, PO Box 833, Newcastle NSW 2300, Australia

Full list of author information is available at the end of the article
} 


\section{Background}

\section{Identification of psychosis risk}

For the past 25 years psychosis research among young people has tended to focus on identifying risk factors and providing options for early intervention for individuals in the initial stages of illness. The period to which the term 'Ultra High Risk' (UHR) relates is between the first noticeable changes in experience or behaviour and the appearance of overt psychotic symptoms [1]. The existing UHR criteria require that a young person (typically aged 14-30 years) who has been referred for mental health $(\mathrm{MH})$ problems meets one or more of the following criteria: a) has experienced sub-threshold attenuated psychotic symptoms (APS); b) has experienced brief limited intermittent psychotic symptoms (BLIPS) - that is, episodes of psychotic symptoms that have lasted less than a week and resolved spontaneously; and/or c) meets trait and state risk factor criteria - having a first degree relative with a psychotic disorder or schizotypal personality disorder, whilst also experiencing a significant decline in functioning during the previous year [1-4]. Similar UHR criteria have been widely used throughout the world, together with various terms such as 'clinical high risk', 'at risk mental state (ARMS)', or 'prodromal criteria' [5,6]. As these terms are reasonably interchangeable, for the purposes of this paper, the term UHR will be used.

\section{Potential benefits and shortcomings from identifying psychosis risk status}

While some centres and researchers have highlighted the importance of assessing UHR status, in order to provide early intervention, recent studies have also indicated that many individuals classified as UHR will not convert to psychosis, and equally, those who are deemed not at risk at the time of assessment may eventually develop the disorder [7-9]. For example, these findings have fuelled an ongoing debate in the Australian and New Zealand Journal of Psychiatry around the issue of establishing psychosis risk and the provision of additional early intervention services in Australia for people who are either at risk or have recently experienced their first episode [10-18].

Yung [12] defined early intervention as timely provision of professional help to an individual with a first episode of psychosis, arguing that much of the deterioration seen in clients with schizophrenia and other psychotic disorders is likely to be due to psychosocial factors that operate in the first few years of illness (as opposed to inherent biological processes). These factors include: disruption to education and career trajectory; family stress or breakdown; loss of friendships; depression; stigma; disruption of personality development; fear of relapse; substance misuse; homelessness; and post-traumatic stress disorder [12]. A recent comprehensive review of the psychosis risk literature [6] reinforces this view, demonstrating that clients at risk show psychopathologic, functional, neurocognitive and structural abnormalities. Additionally, another recent review of cognitive impairments and underlying pathophysiology [19] suggests that the early signs of structural and functional brain deficits among UHR clients are predictive of clinical outcomes. However, it is unclear to what extent these findings reflect a range of psychiatric disorders, psychological distress in general, or unique features of psychosis; hence, more longitudinal research is required comparing clients at risk who develop a psychotic disorder with those who do not.

Tanskanen and colleagues [20] conducted a recent qualitative study of help-seeking for a first psychosis episode, examining the perceptions of service users and carers. Common alternative explanations for psychotic symptoms included: substance misuse; stress; physical illness; and other psychological conditions [20]. These factors often add complexity to the clinical presentation and to the provision of early intervention. Yung [12] argues that provision of early intervention can either prevent these phenomena from occurring or minimise their impact on the individual. In addition, McGorry provides evidence from meta-analyses showing that early intervention reduces the risk of transition to psychosis to less than $10 \%$, with psychological treatments such as cognitive behaviour therapy being as effective as antipsychotic medications [14,21].

A shorter duration of untreated psychosis (DUP) can reduce the initial psychosocial damage and the risk of traumatic forms of service entry and suicidal behaviours $[22,23]$. However, evidence for the efficacy of public health and educational campaigns in reducing DUP is mixed [24,25]. Comparable initiatives in Australia [26] and Canada [27] have not demonstrated the same benefits and further fuelled the debate about early intervention in psychosis. Castle [17] suggests that in Australia there is no good evidence that intervening early has any major effect on the longitudinal course of psychosis and certainly cannot prevent schizophrenia. However, regardless of whether clients meet UHR criteria, or are treated by specialist or generalist $\mathrm{MH}$ services, most are likely to present with sufficiently serious $\mathrm{MH}$ conditions to warrant treatment [15].

\section{Comorbidity considerations}

There are high levels of comorbid drug and alcohol problems among individuals with schizophrenia and other psychotic disorders [28-30], as well as comorbid depression, dysthymia, and anxiety disorders [31], contributing to poorer global functioning and other negative outcomes [28]. Both alcohol and cannabis abuse/dependence among individuals with psychosis have been specifically associated with male gender and younger age [28-30]. 
Research suggests that the majority of clients presenting to services who meet UHR criteria in fact present with anxiety disorder or major depression [32-34]. Moreover, psychotic like experiences have also been linked with traumatic stress disorders and substance use/dependence [35]. Similarly, there is evidence of shared underlying features, such as altered cognitions, disturbed social and emotional functioning [36,37]. Additional support for common factors underlying both affective and psychotic pathology, or for reciprocal causal influence, comes from longitudinal studies showing subclinical psychotic experiences predict not only subsequent onset of psychotic disorders [38] but also affective disorders, even when psychotic experiences are not considered clinically relevant [39]. The cooccurrence of subclinical psychotic experiences and major depressive disorder also predict poorer outcomes [40]. Consequently, comorbidity issues need to be carefully considered amongst young people at risk for psychosis, as a potential predictor, moderator, or concurrent outcome.

\section{Limited reporting about implementation of specialised psychosis related services}

Despite the relatively long-standing research emphasis on psychosis risk identification, and the potential for early intervention, there have been few published papers about the implementation and evaluation of associated specialised services [41-47]. Two Australian services previously documented are Melbourne's Personal Assessment and Crisis Evaluation (PACE) clinic [42,44] and Newcastle's Psychological Assistance Service (PAS, initial 2 years) [41]. When identifying individuals at risk, or within the early stages of a psychotic illness, most services have applied broadly similar criteria to the PACE clinic $[3,42]$, but often with an additional focus (e.g., early prodromal and basic symptoms [45]; multi-element interventions for early psychosis [47]). Across these services, there have been consistently higher rates of presentations by males (60-70\%), and amongst individuals meeting UHR criteria, attenuated symptoms have been more prominent. Referrals have typically been from $\mathrm{MH}$ services, with the particular pathways being largely determined by the health care systems within which those services operate (e.g., centralised public health systems in Australia and the United Kingdom, versus specialised and university clinics elsewhere).

\section{The current study}

Although transition rates and the prediction of psychosis outcomes are still a central focus of research endeavour [48], there is a growing emphasis on the nature and severity of presenting problems, associated comorbidity, and both psychosis and non-psychosis outcomes [15,34,40]. Against this backdrop, and the limited publications reporting on the implementation of specialised psychosis related services, it is perhaps timely that we report the initial findings from our layered service audit (Layer 1: Baseline profiles).

The current service evaluation study was based on all presentations to a specialised 'Psychological Assistance Service' (PAS, Newcastle) for young people between service commencement in 1997 and December 2007; outcome data (relating to subsequent treatment, service contacts, admissions, transition to psychosis and comorbidity) were collected for a further two years, and will largely be the subject of future papers.

The primary aims of the present paper were threefold: 1) to describe the socio-demographic and clinical characteristics of PAS clients (including their psychosis and UHR status, previous service contacts, hospitalisation rates, and diagnostic and comorbidity profiles), and identify key groups for subsequent comparisons; 2) to document any service level or data collection factors or changes during the audit period that could impact on subsequent outcomes (and need to be considered as potential covariates); and 3) to examine the clinical and other characteristics of those clients who received ongoing treatment by PAS, relative to those who were primarily assessed and referred elsewhere.

Two problems that beset UHR and associated psychosis research relate to the identification of relevant comparison groups and the potential contamination/confounding of baseline and outcome assessments (e.g., where symptoms initially identified as transient at baseline actually continue until the first outcome assessment, and do not represent a new clinical episode or genuine transition). Many studies have contrasted UHR and first episode groups (e.g., $[41,49,50])$. While this is a valuable comparison for assessing underlying characteristics and possible developmental trajectories, it is less useful for examining differential conversion rates, since 'transition to psychosis' by those with UHR is essentially being compared with 'conversion to established psychosis' (generally schizophrenia) by those who already have a psychotic disorder. It is equally as important to examine subsequent transition to psychosis and associated characteristics and comorbidity by those who do not meet either psychosis or UHR criteria on initial presentation to services. By utilising all available service level data (as opposed to discrete assessments conducted solely for research purposes), the current study seeks to identify a clearer set of clinical groups (against which to compare subsequent clinical and service level outcomes for those classified as UHR), together with a better separation of baseline and outcome data.

\section{Methods}

The Psychological Assistance Service (PAS)

PAS was established in Newcastle (Australia) in 1997 and provided a community-based specialist service for 
young people (aged 12-25 years) who may have recently experienced a psychotic or related episode, or who were potentially at increased risk of developing a psychotic disorder. Psychosis risk status assessment was benchmarked against the criteria used by Melbourne's PACE clinic $[2,44]$, with PAS using comparable entry criteria and assessment methods (e.g., for assessing 'at risk mental states (ARMS)'). Typically, this comprised a preliminary risk assessment followed by more intensive assessments conducted over multiple sessions (among those likely to be at increased risk, or with complex or unclear presentations), together with various neuropsychological and self-report measures [41]. Subsequently, PAS adopted a shorter assessment procedure that applied to all presentations, which was based on the PACE clinic's Comprehensive Assessment of At Risk Mental States (CAARMS) [51]. The CAARMS instrument allows several aspects of risk to be coded, including family history, recent deterioration in functioning (e.g., a drop of 30 GAF points in the past 12 months), attenuated psychotic symptoms, and transient self-limited psychotic symptoms of less than one week duration (BLIPS). All (ARMS-based) assessments conducted prior to the introduction of the CAARMS were re-coded to an equivalent format. Approximately one-fifth of clients received ongoing (medium-term) treatment from PAS, which was provided by a small, multidisciplinary team of clinicians. This included psychiatric assessment and review, medication (if required), case management, cognitive behaviour therapy (CBT), family interviews, and/or other therapeutic interventions, as appropriate.

\section{Data sources}

The data for this audit included both paper based and electronic clinical records from three different sources: 1) PAS clinical records; 2) community clinical records; and 3) hospital admission records. These data were processed separately initially, taking note of service delivery dates, and then any duplicate entries or inconsistencies were resolved. A PAS referral date was identified for each client, which was used as the basis for classifying all service occasions (i.e., community presentations or hospital admissions) into one of five timeframes: a) more than 2 years pre-PAS; b) up to 2 years prePAS; c) within two months following PAS referral (which we refer to as the two-month 'PAS presentation window'); d) up to 2 years post-PAS (i.e., beyond the presentation window); and e) more than 2 years post-PAS.

Importantly, 'baseline' classification of clients into groups was based on all available service data up to and including two months post-PAS presentation. Any recorded psychosis episodes with dates before the PAS referral date were regarded as 'existing psychosis' episodes, while those falling (or assessed) within the PAS presentation window were regarded as 'recent psychosis' episodes. Although the term 'first episode psychosis' probably applies to many of the latter episodes, we have avoided using this term here because episode onset and frequency were not always assessed (only by exclusion) and a proportion of the 'existing episodes' would have also been 'first episode psychosis'.

\section{PAS data (presentations: $1997-2007,+2$ years for ongoing treatment profiles and other outcomes)}

Client information was initially translated from paper based service entry books into an electronic client database, which was subsequently matched against records from an existing PAS Access database. There were 2206 presentations to PAS during the audit period, 32 of which were excluded because of insufficient key identifying data (e.g., name or medical record number, referral or presentation dates). Among the remaining 2174 presentations, there were 1997 index presentations (by 1178 male and 819 female clients), with 177 repeat presentations (for separate clinical episodes involving the same clients).

On the basis of their own assessments (including the CAARMS), and other referral and service information, PAS initially classified all assessed clients in terms of their probable psychosis status and, where appropriate, their UHR status (including UHR subgroup status based on attenuated psychotic symptoms of recent onset, BLIPS, and/or trait-state risk factor criteria). The sole source of UHR status information was the PAS assessments, although (as described below) for the current analyses final assignment to groups was based on all available service level data.

\section{Community data (1997-2009)}

These data were extracted from two separate community sources: a) the 'CROOS database' (1997-2002), which was a stand-alone, $\mathrm{MH}$ service specific Access database containing limited client level information, service contacts and diagnoses; and b) the 'CHIME system' (20032009), an electronic database which progressively replaced CROOS from 2002-2003. CHIME is a comprehensive, community based client electronic record integrating data from community health and MH services. Service contacts, diagnostic data, and presenting problems/issues were initially processed separately; however, duplicate records and all admissions for persons younger than 12 years were deleted prior to the data being combined. As individuals varied in the length of time pre- and post-PAS for which service level data might be available (depending on their age at PAS presentation, the year in which they first presented, and the completeness of the relevant data systems), a common metric was adopted for calculating community contact rates, namely the number of service contact days per year (pro-rated for each individual based on the available data window). Similarly, to facilitate data 
aggregation, $\mathrm{MH}$ diagnoses and problems/issues were reclassified into nine common categories (psychosis, depression, anxiety, substance misuse, personality disorder, other $\mathrm{MH}$ problems, psychosocial issues, physical disorders, and other non-MH problems); when removing redundant records (e.g., equivalent diagnostic and problem/issue categories for the same service contact occasion) and for other hierarchical assignments, priority was given to diagnostic information (i.e., ICD-10 diagnoses) over 'issues' based CHIME listings.

\section{Hospital admission records (1993-2009)}

These data were extracted from two regional electronic hospital records systems: HOSPAS (1993-2003) and IPMS (2004-2009); only admissions from 12 years of age onwards were considered. Both systems collected comparable clinical data in terms of demographic information, length of stay, service use and diagnoses; any duplicate records were removed after data aggregation. Diagnoses were also re-classified into the nine common categories described above. Likewise, to adjust for variations in data availability timeframes across individuals, admission rates were calculated as admission days per year.

\section{Ethics and data access approvals}

As noted above, data reported here are from a layered service audit. Most aspects of this project received an exemption from formal review by the Hunter New England (HNE) Human Research Ethics Committee (letter dated March $25^{\text {th }}$ 2008), being viewed as part of an internal, low risk, service evaluation. Project layers involving linkages with other assessments conducted primarily for research purposes, and/or by research students, received separate approvals from the same Ethics Committee (03/12/10/3.16 and 12/11/21/5.06). Access to clinical records and selected databases within HNE MH services was approved by the Area Director of $\mathrm{MH}$ services, including access to PAS records and the CROOS database. Access to regional health databases (e.g., CHIME, HOSPAS, IPMS) was approved by relevant departmental managers from within HNE Local Health District. Project data management and analysis have been undertaken by the MH-READ unit within HNE MH services, of which the first three authors (AMC, TJL, KAS) are members.

\section{Allocation to baseline groups}

The allocation of PAS clients $(\mathrm{N}=1997)$ to baseline clinical groups was hierarchical in nature, with priority given to any evidence of psychosis in the period up to and including the two-month PAS presentation window. This facilitated a more accurate classification of clients into five groups: Group A - 'existing psychosis' prior to the PAS referral date (based on all available evidence from community and admission records, PAS referral information and assessments); Group B - 'recent psychosis', based on similar information and assessments but with no evidence of psychosis prior to the referral date (only during the PAS presentation window); Group C - 'Ultra-High Risk (UHR)' group, based on PAS's clinical assessment (and non-membership of groups A or B); Group D - 'nonpsychosis $M H$ disorders' group (e.g., depression, anxiety, substance misuse, personality disorder), based on all available service level data and assessments (and nonmembership of groups A to C); and Group E - labelled as 'uncertain' ( $\mathrm{N}=250$ clients or $12.5 \%)$, about whom limited information was available (but with no basis for allocation to groups A to D), including individuals deemed not suitable for full assessment (13.9\% of Group E), who refused assessment (13.4\%), who were referred elsewhere (42.9\%), or who had minimal or no contact with PAS (29.8\%). Consequently, Group E was omitted from several of the analyses (e.g., when socio-demographic or diagnostic information was required).

\section{Statistical analyses}

Microsoft Excel/Access and SPSS statistical software (Version 17.0; SPSS, Chicago, II, USA) were used for data processing and analyses. Chi-square tests (for categorical variables) and analyses of variance (for continuous variables) were used to examine differences between groups for the demographic variables, diagnostic and comorbidity profiles. In addition, community contacts and admissions were expressed as rates per year for the purposes of describing the data. Univariate and multivariate (two-step hierarchical) logistic regressions were used to examine predictors of treatment intensity within PAS. As a partial control for the number of statistical tests, the threshold for significance was set at $\mathrm{p}<0.01$.

\section{Results}

\section{Sample characteristics}

Table 1 reports selected demographic and referral source information for the PAS clients included in the audit ( $\mathrm{N}=1997)$. Overall, $14.5 \%$ were classified as having an 'existing psychosis' (Group A, N =289), 19.8\% as 'recent psychosis' (Group B, N =395), 9.6\% as UHR (Group C, $\mathrm{N}=191$ ), and $43.7 \%$ as 'non-psychosis $\mathrm{MH}$ disorders' (Group D, N =872); while the remainder (12.5\%) were assigned to the 'uncertain' group (Group E, N =250), having received minimal assessment and with limited or no information about previous contacts with health services. Within the UHR group, $26.2 \%$ reported a family history of psychosis $(\mathrm{N}=50), 69.1 \%$ had attenuated symptoms ( $\mathrm{N}=132)$, and $16.2 \%$ had experienced BLIPS $(\mathrm{N}=31)$.

Overall there were more males $(59.0 \%)$ who presented to PAS, with differential profiles across groups $\left(\chi_{(4)}^{2}=20.0\right.$, $\mathrm{p}<0.001)$, associated with more males in the two psychosis groups. While the sample was relatively young, with 
Table 1 Baseline characteristics of clients presenting to PAS ( $N=1997)$

\begin{tabular}{|c|c|c|c|c|c|c|}
\hline Characteristic (\%) & $\begin{array}{l}\text { Overall } \\
(\mathrm{N}=1997)\end{array}$ & $\begin{array}{l}\text { A: Existing psychosis } \\
\text { (in pre-PAS period) } \\
(\mathrm{N}=\mathbf{2 8 9})\end{array}$ & $\begin{array}{l}\text { B: Recent psychosis (during } \\
\text { PAS presentation window) } \\
(\mathrm{N}=395)\end{array}$ & $\begin{array}{l}\text { C: Ultra High Risk } \\
\text { (UHR) group } \\
(\mathrm{N}=191)\end{array}$ & $\begin{array}{l}\text { D: Non-psychosis } \\
\text { MH disorders } \\
(\mathrm{N}=\mathbf{8 7 2})\end{array}$ & $(\mathrm{N}=250)$ \\
\hline Gender (\% males) & 59.0 & 68.5 & 62.8 & 57.1 & 56.3 & 52.8 \\
\hline \multicolumn{7}{|l|}{ Age } \\
\hline Mean (SD) & $19.2(4.5)$ & $21.0(4.7)$ & $19.6(3.8)$ & $17.6(3.0)$ & $18.9(4.6)$ & $19.1(5.5)$ \\
\hline Less than 18 years (\%) & 55.6 & 36.0 & 52.7 & 70.7 & 59.2 & 59.2 \\
\hline \multicolumn{7}{|l|}{ Referral source } \\
\hline Self or family & 18.4 & 5.9 & 12.2 & 16.8 & 23.1 & 28.0 \\
\hline Community MH & 13.5 & 21.1 & 20.3 & 8.9 & 10.7 & 7.2 \\
\hline Hospital & 14.8 & 42.9 & 15.4 & 6.3 & 10.1 & 4.4 \\
\hline GP & 2.7 & 0.7 & 3.5 & 3.1 & 3.2 & 1.6 \\
\hline Other services & 17.5 & 5.9 & 13.7 & 17.8 & 23.2 & 17.2 \\
\hline Unknown & 33.0 & 23.5 & 34.9 & 47.1 & 29.8 & 41.6 \\
\hline $\begin{array}{l}\text { Other demographic } \\
\text { information available }\end{array}$ & 53.6 & 46.4 & 71.9 & 67.5 & 44.6 & - \\
\hline $\begin{array}{l}\text { Characteristics of clients } \\
\text { with available demographic } \\
\text { data (\%) }\end{array}$ & $(\mathrm{N}=936)$ & $(\mathrm{N}=134)$ & $(\mathrm{N}=\mathbf{2 8 4})$ & $(\mathrm{N}=129)$ & $(\mathrm{N}=368)$ & \\
\hline \multicolumn{7}{|l|}{ Marital status } \\
\hline Single & 92.9 & 92.5 & 92.6 & 96.9 & 92.0 & \\
\hline \multicolumn{7}{|l|}{ Educational level } \\
\hline High school only & 86.8 & 86.4 & 84.4 & 89.1 & 87.9 & \\
\hline \multicolumn{7}{|l|}{ Accommodation } \\
\hline Live with family & 77.9 & 81.2 & 78.9 & 81.3 & 74.9 & \\
\hline Live in house/flat & 16.3 & 12.8 & 16.5 & 15.6 & 17.6 & \\
\hline Short term & 5.8 & 6.0 & 4.6 & 3.1 & 7.5 & \\
\hline \multicolumn{7}{|l|}{ Employment status } \\
\hline Employed & 21.1 & 24.6 & 18.4 & 23.0 & 21.2 & \\
\hline Unemployed & 43.8 & 57.5 & 46.3 & 27.8 & 42.4 & \\
\hline Student & 35.2 & 17.9 & 35.3 & 49.2 & 36.4 & \\
\hline
\end{tabular}

an average age of 19.2 years, there were significant differences between groups $\left(\mathrm{F}_{(4,1997)}=19.4, \mathrm{p}<0.001\right)$, with the UHR group being the youngest (averaging 17.6 years). Referral source differences $\left(\chi_{(20)}^{2}=369.2, \mathrm{p}<0.001\right)$ followed a consistent pattern, with $42.9 \%$ of clients with existing psychosis referred by hospitals, $20.3 \%$ of clients with recent psychosis referred by community $\mathrm{MH}$ teams, and higher rates of self-referrals across the other groups (16.8\% - 28.0\%).

The lower portion of Table 1 summarises the other demographic data available for Groups A to D. There were no significant group differences for marital status, accommodation or employment, with the majority of clients being single (92.9\%), living with family (77.9\%), and having completed high school (86.6\%). Employment differences $\left(\chi_{(6)}^{2}=34.3, \mathrm{p}<0.001\right)$ reflected the age profiles, with $49.2 \%$ of the UHR group being students.

\section{Psychosis profiles}

Table 2 presents a breakdown of the psychosis related diagnostic profiles for the two psychosis groups, with individuals potentially allocated to multiple categories using all available information about psychosis episodes. The first seven categories in Table 2 are based on ICD10 diagnoses (from hospital or community records), while the last three are based on psychosis related problems or issues identified in PAS clinical notes or CHIME electronic clinical records. Overall, the vast majority (92.7\%) of those within the existing psychosis group had at least one formal psychosis diagnosis, including $46.7 \%$ with a schizophrenia diagnosis, $33.2 \%$ with an 'unspecified nonorganic psychotic disorder', $21.8 \%$ with an 'acute or transient psychotic disorder', and $20.4 \%$ with bipolar disorder (including mania); additionally, 38.8\% also had at least one psychosis problem/issue identified in other 
Table 2 Diagnostic profiles for psychosis groups

\begin{tabular}{|c|c|c|}
\hline $\begin{array}{l}\text { Diagnostic or problem } \\
\text { category }(\%)\end{array}$ & $\begin{array}{l}\text { A: Existing psychosis } \\
(\mathrm{N}=289)\end{array}$ & $\begin{array}{l}\text { B: Recent psychosis } \\
(\mathrm{N}=395)\end{array}$ \\
\hline Formal ICD-10 diagnoses & {$[92.7]$} & {$[63.8]$} \\
\hline 1. Schizophrenia & 46.7 & 24.5 \\
\hline $\begin{array}{l}\text { 2. Persistent delusional } \\
\text { disorder }\end{array}$ & 8.0 & 2.0 \\
\hline $\begin{array}{l}\text { 3. Acute or transient psychotic } \\
\text { disorder }\end{array}$ & 21.8 & 22.0 \\
\hline 4. Schizoaffective disorder & 6.9 & 1.7 \\
\hline $\begin{array}{l}\text { 5. Other nonorganic psychotic } \\
\text { disorder }\end{array}$ & 1.4 & 0.7 \\
\hline $\begin{array}{l}\text { 6. Unspecified nonorganic } \\
\text { psychotic disorder }\end{array}$ & 33.2 & 21.5 \\
\hline $\begin{array}{l}\text { 7. Bipolar disorder } \\
\text { (including mania) }\end{array}$ & 20.4 & 7.1 \\
\hline Other clinical records (e.g., CHIME) & {$[38.8]$} & [49.9] \\
\hline 8. Schizophrenia (problem/issue) & 11.1 & 18.9 \\
\hline 9. Bipolar (problem/issue) & 5.2 & 9.4 \\
\hline $\begin{array}{l}\text { 10. Other psychosis } \\
\text { (problem/issue) }\end{array}$ & 26.3 & 21.7 \\
\hline
\end{tabular}

Note: Tabled values are the percentage of each group with any evidence of that diagnosis/problem during the time period, based on all available assessments (A: 698; B: 581), with assignments not mutually exclusive; aggregate psychosis rates for formal diagnoses and other clinical records are shown in square brackets; $\mathrm{CHIME}$, electronic clinical record system used by community based services.

clinical records. Among the recent psychosis group, the equivalent categories had generally lower rates, with 63.8\% having a formal psychosis diagnosis (including $24.5 \%$ with schizophrenia and $7.1 \%$ with bipolar disorder); moreover, half (49.9\%) of the recent psychosis group also had at least one psychosis problem/issue identified in other records.

To further examine within-psychosis comorbidity, we pooled the formal ICD-10 diagnoses and the corresponding problems/issues identified in the other clinical records. For example, within the existing psychosis group, 52.9\% $(\mathrm{N}=153)$ were identified as having schizophrenia and 23.2\% ( $\mathrm{N}=67)$ with bipolar disorder, with only a small overlap between these conditions $(\mathrm{N}=17$, or $5.9 \%)$. Similarly, within the recent psychosis group, the corresponding aggregated rates were: schizophrenia, $41.5 \%(\mathrm{~N}=164)$; bipolar disorder, $15.7 \%(\mathrm{~N}=62)$; and overlap, $1.5 \%(\mathrm{~N}=6)$. Thus, the within-psychosis overlap between the schizophrenia and bipolar disorder categories was minimal.

In view of the ongoing debate within the clinical and research literature about what constitutes the prodromal phase of illness and transition to psychosis, we also examined the timing of psychosis episodes among clients allocated to the recent psychosis group. With respect to the first reported episodes within the PAS presentation window ( $\mathrm{N}=395)$, half $(57 \%)$ were identified from PAS clinical information, 9.9\% came from inpatient records, and $33.2 \%$ from community records. Among the subset with detailed service delivery or assessment date information $(\mathrm{N}=298,75.4 \%)$, the average time interval was 13.2 days post-PAS referral (with a median of 9 days); two-thirds (66.4\%) of these assessments occurred within two weeks of PAS referral, while only $12.5 \%$ occurred more than four weeks after the referral date. The timing of these episodes (based solely on assessment dates) suggests that for the majority of clients the psychosis symptoms that were detected were probably also present at the PAS referral date and initial assessment rather than developing subsequently.

\section{Comorbidity profiles}

As shown in Table 3, PAS clients had high levels of comorbidity across the various 'baseline' assessments and service presentations. Overall, there were significant group differences for every condition, except personality disorder. The highest levels of depression (62.3\%) and anxiety (42.9\%) were identified among the UHR group, while substance misuse $(52.9 \%)$ and psychosocial issues (70.2\%) were particularly notable among the existing psychosis group. The lower rate of substance misuse problems within the UHR group (6.8\%) is not surprising, since $70.7 \%$ were under the age of 18 years at PAS presentation. Conversely, the relatively high rates of physical disorders (37.7\%) and other non-MH problems (25.6\%) among the existing psychosis group are noteworthy, considering that their mean age was only 21 years.

\section{Service utilisation}

Table 4 reports community contacts and hospital admission profiles for the five clinical groups. The first row of the table shows the estimated availability period for medical records, on which community contact and hospital admission rates were based; which, once again, partially reflects differences in the mean age across groups and variations across PAS presentation years. Overall, the PAS clients $(\mathrm{N}=1997)$ had 6.3 years of baseline data available, amounting to 9618 community contacts, or the equivalent of approximately one contact per client per year with any adult MH service. These rates are somewhat inflated by the high number of contacts within the short, two-month presentation window (which averaged over one contact per month). However, comparisons across groups are appropriate within the same metric; more generally, service contact rates are often inflated when sample selection is based on an index event (in this case, presentation to PAS). Those in the existing psychosis group had the highest aggregate contact rates per client per year (1.25), while the UHR and recent psychosis groups had the highest level of PAS contact during the presentation window (averaging 3.16 and 2.96 contacts, respectively). In relation to hospital admissions, $84.1 \%$ of 
Table 3 Baseline comorbidity profiles for PAS clients ( $N=1747)$

\begin{tabular}{|c|c|c|c|c|c|c|}
\hline Comorbid condition (\%) & $\begin{array}{l}\text { Overall (Excluding E: } \\
\text { Uncertain group) } \\
\text { (N=1747) }\end{array}$ & $\begin{array}{l}\text { A: Existing } \\
\text { psychosis } \\
(\mathrm{N}=289)\end{array}$ & $\begin{array}{l}\text { B: Recent } \\
\text { psychosis } \\
(\mathrm{N}=395)\end{array}$ & $\begin{array}{l}\text { C:Ultra High Risk } \\
\text { (UHR) group } \\
(\mathrm{N}=191)\end{array}$ & $\begin{array}{l}\text { D: Non-psychosis } \\
\text { MH disorders } \\
(\mathrm{N}=872)\end{array}$ & $\begin{array}{l}\text { Statistical comparison } \\
\text { (Groups } A \text { to } D \text { ) }\end{array}$ \\
\hline Depression & 43.8 & 36.7 & 49.6 & 62.3 & 39.4 & $X_{(3)}^{2}=44.7^{* *}$ \\
\hline Anxiety & 25.1 & 21.5 & 34.2 & 42.9 & 18.3 & $X_{(3)}^{2}=72.7^{* *}$ \\
\hline Substance misuse & 26.5 & 52.9 & 37.0 & 6.8 & 17.3 & $X_{(3)}^{2}=201.7^{* *}$ \\
\hline Personality disorder & 17.1 & 16.6 & 16.2 & 20.9 & 16.7 & $X_{(3)}^{2}=2.3$ \\
\hline Other MH problems^ & 67.3 & 68.9 & 55.7 & 67.5 & 72.0 & $X_{(3)}^{2}=33.3^{* *}$ \\
\hline Psychosocial issues & 40.4 & 70.2 & 39.2 & 41.9 & 30.7 & $X_{(3)}^{2}=141.1^{* *}$ \\
\hline Physical disorders & 14.0 & 37.7 & 13.2 & 6.3 & 8.3 & $X_{(3)}^{2}=168.3^{* *}$ \\
\hline Other Non-MH problems & 15.1 & 25.6 & 14.2 & 7.3 & 13.8 & $X_{(3)}^{2}=35.3^{* *}$ \\
\hline
\end{tabular}

Note: $\wedge$ Within this category, the proportionate breakdown of conditions was: $70.1 \%$ attentional problems, $8.9 \%$ service related problems, $6.2 \%$ adjustment disorders, $5.6 \%$ childhood disorders, $1.6 \%$ intellectual disability, and $7.6 \%$ other problems (other behavioural and MH disorders, cognitive related problems, neurological disorders). Statistical significance: * $p<0.01,{ }^{* *} p<0.001$.

the existing psychosis group had at least one MH admission, averaging 3.39 admission days per client per year, well above the other groups.

Figure 1 illustrates the pattern of presentations to PAS across the audit period. At least two trends are worthy of comment. Firstly, there was an overall reduction in the number of presentations from 2004 onwards, which coincided with service relocation, staffing alterations, and changes in referral and assessment procedures. Secondly, over time there was a proportionate reduction in the number of clients assigned to the uncertain group, which occurred for a mixture of reasons: improved access to electronic records; improvements in clinical documentation and assessment procedures (including the change to a more uniform, CAARMS based assessment); and the simple increased volume of potential pre-PAS records

Table 4 Baseline community contacts and admission profiles by PAS clients ( $N=1997)$

\begin{tabular}{|c|c|c|c|c|c|c|}
\hline & $\begin{array}{l}\text { Overall } \\
(\mathrm{N}=1997)\end{array}$ & $\begin{array}{l}\text { A: Existing } \\
\text { psychosis } \\
(\mathrm{N}=289)\end{array}$ & $\begin{array}{l}\text { B: Recent } \\
\text { psychosis } \\
(\mathrm{N}=395)\end{array}$ & $\begin{array}{l}\text { C: Ultra High Risk } \\
\text { (UHR) group } \\
(\mathrm{N}=191)\end{array}$ & $\begin{array}{l}\text { D: Non-psychosis } \\
\text { MH disorders } \\
(\mathrm{N}=872)\end{array}$ & $\begin{array}{l}\text { E: Uncertain } \\
(\mathrm{N}=250)\end{array}$ \\
\hline $\begin{array}{l}\text { Estimated availability of medical records - mean } \\
\text { (median) years }\end{array}$ & $6.3(5.9)$ & $7.7(7.5)$ & $6.6(6.1)$ & $5.4(5.1)$ & $6.2(5.8)$ & $5.5(5.4)$ \\
\hline \multicolumn{7}{|l|}{ Community contacts } \\
\hline Total contacts & 9618 & 2499 & 2253 & 980 & 3631 & 255 \\
\hline $\begin{array}{l}\text { Average contact days per year (excluding } \\
\text { presentation window) }\end{array}$ & $0.98(0.31)$ & $1.25(0.57)$ & $0.99(0.28)$ & $1.38(0.37)$ & $0.99(0.31)$ & $0.33(0.00)$ \\
\hline $\begin{array}{l}\text { Average number of PAS contacts within } \\
\text { presentation window }\end{array}$ & 2.25 & 2.32 & 2.96 & 3.16 & 2.07 & 1.01 \\
\hline \multicolumn{7}{|l|}{ All admissions (Min. age 12 years) } \\
\hline Total admissions & 1788 & 674 & 357 & 87 & 601 & 69 \\
\hline Total beddays & 12748 & 6739 & 3042 & 297 & 2452 & 218 \\
\hline Any admission (\%) & 40.7 & 85.5 & 45.1 & 26.7 & 33.1 & 18.8 \\
\hline Average admission days per year & 1.08 & 3.62 & 1.48 & 0.30 & 0.48 & 0.17 \\
\hline \multicolumn{7}{|l|}{ MH admissions } \\
\hline Total admissions & 1090 & 537 & 210 & 40 & 303 & 0 \\
\hline Total beddays & 10787 & 6343 & 2438 & 214 & 1792 & - \\
\hline Any admission (\%) & 28.2 & 84.1 & 33.4 & 12.0 & 19.0 & 0.0 \\
\hline Average admission days per year & 0.91 & 3.39 & 1.23 & 0.22 & 0.35 & - \\
\hline
\end{tabular}

Note: The relevant timeframe includes the pre-PAS period plus the two-month PAS presentation window (i.e., presentations to youth and adult services, and admissions from the age of 12 years); average contact/admission days per year includes individuals with zero values; group E's known contacts with MH services are largely limited to PAS. 


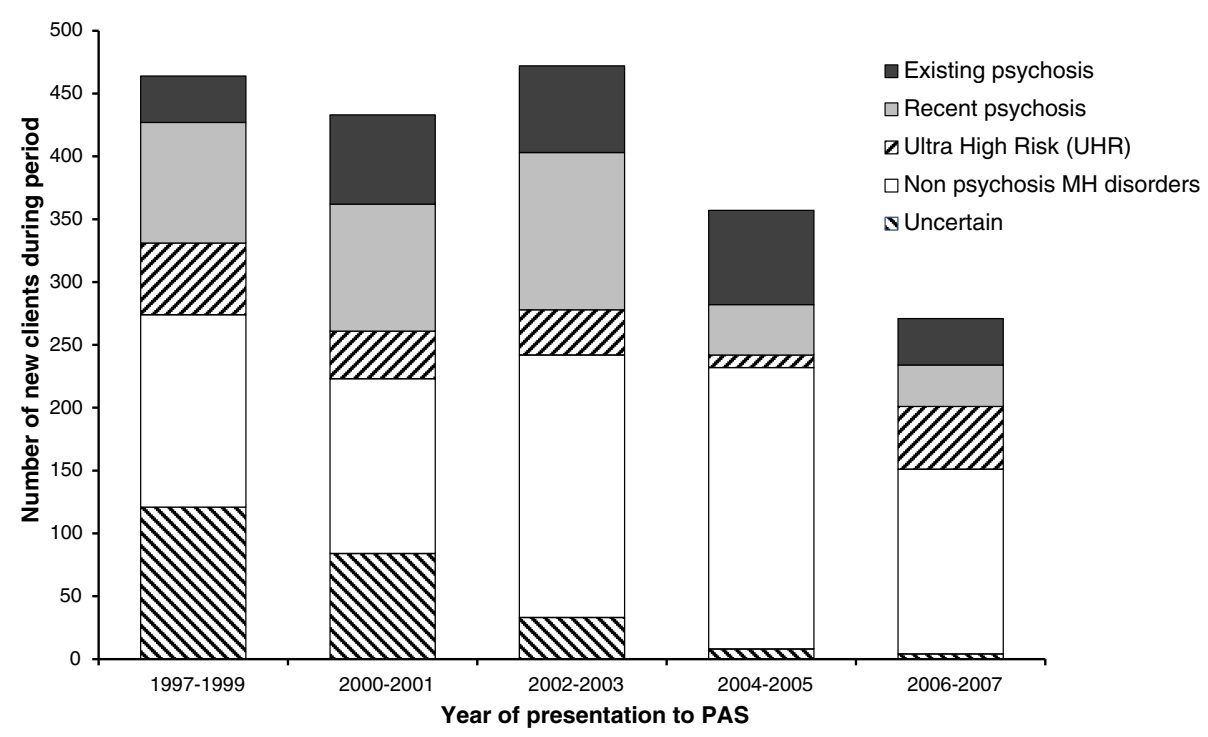

Figure 1 Pattern of presentations to PAS by year.

per client as time advances (given the fixed starting dates for the available electronic databases - 1993 for hospital records and 1997 for community records).

\section{Potential confounders}

Based on the service changes noted above, the various data collection methods and changes across the audit period, and the preliminary analyses, a small set of six potential covariates was selected (that could impact on subsequent outcomes): gender (male: $\mathrm{N}=1178$; female: $\mathrm{N}=819$ ); age group (under 18 years: $\mathrm{N}=1111 ; 18+$ years: $\mathrm{N}=886)$; service year block (1997-2003: $\mathrm{N}=1369$; 20042007: $\mathrm{N}=628$ ); PAS treatment status (assessment only: $\mathrm{N}=1593$; some ongoing treatment: $\mathrm{N}=404$ ); and the length of potential data availability windows per client (pre-PAS plus presentation window: mean $=6.32, \mathrm{SD}=2.82$, range $=0.17$ to 14.93 years; post-PAS: mean $=7.40$, $\mathrm{SD}=2.86$, range $=1.86$ to 12.76 years).

\section{PAS treatment status}

The uncertain group (Group E) was excluded from the analysis of PAS treatment status, due to the absence of information about comorbidity, leaving $\mathrm{N}=1747$ clients in this analysis. During the first 26 months after PAS referral (i.e., the presentation window plus 2 years), the average number of PAS contacts was $4.86(\mathrm{SD}=6.89$, median $=2$, range 1 to 64 ); three-quarters $(76.4 \%)$ of which occurred within 8 months of PAS referral. For convenience, we identified two sub-groups: those who primarily received an assessment (i.e., with 6 or fewer contacts; $\mathrm{N}=1342$, mean $=2.11$, median $=1$ contact $)$; and those receiving some ongoing treatment $(\mathrm{N}=404$, or $23.1 \%$, mean $=13.98$, median $=10$ contacts). The outcome variable for the logistic regression analyses was treatment status (0: assessment only $v s .1$ : ongoing treatment), the other five potential confounders listed above were included as covariates in the multivariate analysis (at step 1), and there were nine main predictors (at step 2): clinical group, with nonpsychosis MH disorders (Group D) as the reference group, and the eight baseline comorbidity variables identified in Table 3 (categorized as 0: absent vs. 1: present).

As shown in Table 5, relative to those with nonpsychosis $\mathrm{MH}$ disorders (12.3\% receiving PAS treatment), there were significantly higher $(\mathrm{p}<0.001)$ rates of ongoing treatment among the existing psychosis $(25.6 \%$, Adjusted Odds Ratio, AOR $=3.40$ ), recent psychosis $(33.4 \%$, AOR $=5.80)$ and UHR groups $(47.6 \%$, AOR $=9.57)$. In addition, higher ongoing treatment rates were experienced by those with depression $(28.5 \%, \mathrm{AOR}=1.54, \mathrm{p}=0.002)$ or anxiety $(33.7 \%, \mathrm{AOR}=1.62, \mathrm{p}=0.002)$, and lower rates by those with substance misuse $(17.3 \%, \mathrm{AOR}=0.53)$. There was also a tendency for those with other comorbid $\mathrm{MH}$ problems to have higher treatment rates $(28.1 \%$, $\mathrm{AOR}=1.59, \mathrm{p}=0.010)$. Psychosocial issues, physical disorders and other non-MH problems were not significantly associated with treatment by PAS. In short, PAS was more likely to provide treatment to those at risk for or experiencing psychosis and to those with greater distress (e.g., anxiety/depression) or dysfunction (e.g., attentional problems), a treatment pattern that is consistent with the service's broad specialisation.

\section{Discussion}

Who presented to PAS

PAS in Newcastle and the PACE outpatient clinic in Melbourne [2] were deliberately established with generic 
Table 5 Relationships between baseline client characteristics and receipt of ongoing treatment by PAS ( $N=1747$ )

\begin{tabular}{|c|c|c|c|c|c|}
\hline Baseline characteristic & $\begin{array}{l}\% \text { Receiving ongoing } \\
\text { PAS treatment }\end{array}$ & $\begin{array}{l}\text { Unadjusted Odds } \\
\text { Ratio (OR) }\end{array}$ & $99 \% \mathrm{Cl}$ & $\begin{array}{l}\text { Adjusted Odds } \\
\text { Ratio (AOR) }\end{array}$ & $99 \% \mathrm{Cl}$ \\
\hline Gender: Male & 23.2 (vs. 23.0) & 0.98 & $(0.73,1.32)$ & 0.89 & $(0.64,1.26)$ \\
\hline Age: Less than 18 years & 26.1 (vs. 19.5) & $1.45^{* *}$ & $(1.07,1.96)$ & 1.05 & $(0.59,1.87)$ \\
\hline \multicolumn{6}{|l|}{ Diagnostic group } \\
\hline Existing psychosis & 25.6 & $2.46^{* *}$ & $(1.59,3.81)$ & $3.40^{* *}$ & $(2.11,5.48)$ \\
\hline Recent psychosis & 33.4 & $3.58^{* *}$ & $(2.44,5.25)$ & $5.80^{* *}$ & $(3.75,8.96)$ \\
\hline Ultra high risk & 47.6 & $6.50^{* *}$ & $(4.11,10.28)$ & $9.57^{* *}$ & $(5.66,16.18)$ \\
\hline Non-psychosis MH disorders & 12.3 (ref) & 1.00 & & 1.00 & \\
\hline \multicolumn{6}{|l|}{ Comorbid condition ${ }^{*}$} \\
\hline Depression & 28.5 (vs. 18.9) & $1.70^{* *}$ & $(1.27,2.28)$ & $1.54^{*}$ & $(1.07,2.22)$ \\
\hline Anxiety & 33.7 (vs. 19.6) & $2.09^{* *}$ & $(1.52,2.86)$ & $1.62^{*}$ & $(1.09,2.39)$ \\
\hline Substance misuse & 17.3 (vs. 25.2) & $0.61^{* *}$ & $(0.43,0.88)$ & $0.53^{* *}$ & $(0.33,0.84)$ \\
\hline Personality disorder & 23.5 (vs. 23.1) & 1.02 & $(0.69,1.50)$ & 0.87 & $(0.54,1.39)$ \\
\hline Other MH problems^ & 28.1 (vs. 12.8) & $2.67^{* *}$ & $(1.85,3.84)$ & $1.59^{*}$ & $(1.00,2.54)$ \\
\hline Psychosocial issues & 22.1 (vs. 23.8) & 0.90 & $(0.67,1.22)$ & 0.81 & $(0.54,1.21)$ \\
\hline Physical disorders & 29.0 (vs. 22.2) & 1.43 & $(0.96,2.12)$ & 1.20 & $(0.70,2.03)$ \\
\hline Other Non-MH problems & 22.3 (vs. 23.3) & 0.94 & $(0.62,1.43)$ & 0.66 & $(0.39,1.11)$ \\
\hline
\end{tabular}

Note: Significance tests were based on Wald statistics: ${ }^{*} \mathrm{p}<0.01,{ }^{* *} \mathrm{p}<0.001$; adjusted analyses controlled for all tabled variables, plus service year block and available data windows (pre-PAS). ${ }^{*}$ Includes history of comorbid conditions or concurrent conditions present at the time of assessment. $\wedge$ See Table 3 for further details.

names, to reduce potential stigma and to encourage young people experiencing a range of difficulties to attend. More recently, similar services around the world (and those linked to research programs, in particular) have tended to use more selective referral networks and screening processes to identify a narrower range of potential clients. For the problems that comprised the primary PAS target groups, the yield across the audit period was considered reasonable (existing/recent psychosis yield: $684 / 1997$ or $34.3 \%$; UHR yield: $191 / 1997$ or 9.6\%). However, compared to the other psychosis-related services described earlier, PAS had a much higher percentage of ostensibly non-psychosis related presentations $(872 / 1997$ or $43.7 \%)$, largely reflecting differences in health care systems and referral/assessment processes; which, on the positive side, provided a naturalistic comparison group for examining future transition to psychosis. PAS also developed a local reputation for undertaking comprehensive diagnostic assessments, which may have accounted for some referrals of complex cases (with or without a possible psychosis).

There was a higher overall percentage of males (59\%) presenting to PAS, which is consistent with similar services elsewhere (e.g., [45]), and the majority of clients (55.6\%) were less than 18 years of age. Two-thirds of clients (68.5\%) with an existing psychosis were male, and they also experienced the highest rates of comorbid substance misuse (52.9\%), psychosocial (70.2\%), physical health (37.7\%) and other non-MH (25.6\%) problems, and $\mathrm{MH}$ admissions (84.1\%); these findings are consistent with the profiles highlighted in recent Australian National MH Report Cards [52] for individuals with an established serious mental illness. With respect to diagnosis, almost half (46.7\%) of those with existing psychosis received a schizophrenia diagnosis, compared with one-quarter $(24.5 \%)$ of the recent psychosis group; this pattern probably reflects a mixture of illness stage differences (e.g., evidenced by different comorbidity profiles - see Table 3 ) and data source differences (e.g., diagnostic/assessment practice differences associated with variations in the rates of previous hospital admissions and subsequent referrals - see Tables 1 and 4). Notwithstanding, subsequent conversion rates to schizophrenia amongst the other members of the recent psychosis group (i.e., not presently identified as having a schizophrenia diagnosis or problem) could be a worthwhile additional component in future analyses.

Among the UHR group, half of whom (49.2\%) were students, there were high rates of attenuated psychotic symptoms (69.1\%), in accord with previous studies (e.g., [45,53]); likewise, the BLIPS rate $(16.2 \%)$ was approximately midway between the older and more recent naturalistic studies reviewed by Simon and colleagues [9]. There were also relatively high rates of comorbid depression (62.3\%), anxiety (42.9\%), and attentional and related problems $(67.5 \%)$, which may have precipitated service presentation at that time; indeed, the majority of this 
group's baseline community contacts $(604 / 980$ or $61.6 \%)$ with $\mathrm{MH}$ services were with PAS. Comorbidity profiles among the UHR group were also generally comparable to those reported elsewhere [32-34], with the low rate of substance misuse problems $(6.8 \%)$ consistent with their mean age of 17.6 years. While such problems typically go beyond UHR criteria, they are the focus of everyday clinical attention and contribute to the reasons for clients seeing help [5]. Ongoing monitoring of risk, and any signs of deterioration, can be undertaken while simultaneously addressing these presenting problems [5].

Reductions in annual presentations to PAS and in the percentages of clients assigned to the 'uncertain' category (see Figure 1) are reflective of service, assessment, and data accessibility changes over time, and not an underlying change in the relevant regional population. However, such changes, together with the observed baseline differences between the clinical groups in sociodemographic characteristics (Table 1), comorbidity profiles (Table 3), and involvement in ongoing PAS treatment (Table 5), highlight the fact that these potential confounders need to be carefully taken into account in future analyses of PAS outcomes (such as comparisons between groups in transition rates and subsequent comorbidity and service utilisation).

\section{Who received treatment}

Several factors are likely to have contributed to PAS treatment patterns. Firstly, the service's major focus on those at risk for or experiencing psychosis is reflected in the higher percentages receiving ongoing treatment within the UHR (47.6\%) and recent psychosis (33.4\%) groups. Secondly, the observed associations between higher ongoing treatment rates and comorbid depression/ anxiety and other $\mathrm{MH}$ problems, but not substance misuse, may partially reflect the nature of the psychological treatments likely to be offered (such as CBT), relative to other specialised services to which PAS could refer (e.g., substance misuse services), together with specific concerns for clients experiencing greater distress or dysfunction at presentation.

Those receiving ongoing PAS treatment averaged approximately one session every 8 weeks during the first two years post-presentation; however, in practice, more intensive treatment was delivered during the first six months, followed by periodic review. Having contact with PAS as part of an early intervention strategy might have been beneficial to these clients, especially with respect to education about mental illness, reducing stigma, or providing diagnostic information. In any event, on average, clients who received ongoing PAS treatment appear to have had either more complex or more symptomatic presentations.

As noted earlier, in some instances clients were seen by PAS primarily for the clarification of diagnostic issues, which would be expected to occur more frequently among those displaying comorbidity. Further, research evidence suggests that symptoms of depression and anxiety are present in the majority of clients with schizophrenia, and perhaps these symptoms could be used to identify distinct clinical subgroups among those with psychosis [40]. Moreover, recent studies have shown that anxiety disorders, particularly social anxiety, are highly prevalent and contribute significantly to a reduction in quality of life, particularly social isolation, feelings of helplessness, and lower self-esteem $[31,35]$.

\section{Future directions}

The current paper is largely descriptive in nature and we acknowledge that it is difficult to directly compare psychosis related services operating in different countries and within different health care models, which may partially account for the limited number of published papers documenting the implementation and evaluation of such services. Notwithstanding, we encourage others to undertake similar comprehensive service audits, primarily because they assist in the review and refinement of services, but also because they stimulate consideration and investigation of related research, treatment and translational issues. Such evaluations also need to both inform and be mindful of strategic changes in health service delivery for young people that are currently being undertaken in many countries (e.g., eHealth based initiatives). In Australia, for example, a range of 'headspace centres' have now been established, designed as "highly accessible, youth-friendly, integrated service hubs that provide evidence-based interventions and support to young people aged 12-25 years around their mental health, health and wellbeing needs" [54].

It may be an obvious methodological observation, but it is worth noting again that different patterns of comparisons between clinical groups, ideally across multiple time points, can provide different insights about the underlying problems. So, for example, comparisons within UHR groups between those experiencing and those not experiencing a certain outcome, such as transition to psychosis, or UHR remission [9], can aid our understanding of potential mediators and/or contextual or environmental factors at play; while comparisons between UHR and first episode groups can potentially help to identify some of the prerequisite conditions or early changes associated with the disorder of interest. In the current service evaluation project, there is a further opportunity to utilise a relatively novel comparison group, those with non-psychotic MH disorders (and non-UHR) at baseline, the largest subgroup presenting to PAS. This will enable us to explore questions in future papers such as the following: do UHR individuals have differential psychosis transition rates, or experience different comorbidity or 
service outcomes, compared to those with similar sociodemographic characteristics who presented to the same services during the same time period, but amongst whom neither psychosis nor associated risk was evident?

\section{Strengths and limitations}

While the current dataset provides a basis for comparing several groups of young clients, who are presumably at various illness stages, it nevertheless draws from initial presentations to a single Australian psychosis related service. There are both advantages and disadvantages to using real-world service level data, as opposed to data collected within a formal research framework, which largely boil down to breadth versus depth issues. Service level data is particularly useful for accessing accurate information about service contacts, admissions, presenting problems, and so on, over extended periods of time, relative to self-reported research measures. Larger sample sizes, a lower likelihood of selection biases (e.g., by considering all presentations), and minimal exclusion criteria (e.g., retention of those not meeting UHR criteria), are inherent strengths of service level data.

However, the quality and availability of service level data can be variable. In our case, we used all available baseline service level data for a period exceeding a decade; moreover, for each individual, we essentially looked beyond a single assessment timepoint to a service based window in time (for many clients, from approximately $12+$ years of age to service presentation). On the other hand, research studies typically use standardised scales and structured assessments to more comprehensively assess clinical characteristics, risk factors, treatment fidelity, and selected outcomes. For example, within the current project, one of the obvious limitations was the lack of access to detailed comparative information about current symptomatology, illness chronicity, specific treatments received, or medication usage.

\section{Conclusions}

We have successfully extracted and processed a large amount of service level data (from multiple sources) relating to presentations over a decade to a specialised service for young people experiencing or at increased risk for psychosis. This has facilitated the identification of two broad groups - those who have already experienced at least one episode of psychosis $(\mathrm{N}=684$, subcategorised as existing or recent psychosis) and those without any such episodes, but who vary in their assessed levels of risk for psychosis $(\mathrm{N}=1313$, sub-categorised as UHR, non-psychosis MH disorders, or uncertain). Observed differences between these groups were largely consistent with expectations based on the research literature (e.g., a high percentage of males; moderate to high levels of comorbidity, especially amongst those with existing psychosis; and high rates of attenuated psychotic symptoms, depression and anxiety among the UHR group). Unlike other specialised psychosis-related services, a substantial percentage of PAS presentations displayed neither a psychotic disorder nor an increased risk. It is anticipated that this sub-group will provide a valuable reference point for future analyses, against which to contrast the health trajectories of the UHR and recent psychosis groups in particular.

\section{Abbreviations \\ AOR: Adjusted odds ratio; APS: Attenuated psychotic symptoms; RMS: At risk mental state; BLIPS: Brief limited intermittent psychotic symptoms; CAARMS: Comprehensive Assessment of At Risk Mental States; CBT: Cognitive behaviour therapy; CHIME: Clinical information and management exchange; CROOS: Community register of occasions of service; DSM-IV: Diagnostic and Statistical Manual of Mental Disorders - Version IV; DUP: Duration of untreated psychosis; GAF: Global assessment of functioning; HOSPAS: Hospital patient administration system; HNE: Hunter New England (health district, Australia); ICD-10: International Classification of Diseases (Version 10); IPMS: Inpatient management system; MH: Mental Health; MH-READ: Research Evaluation Analysis and Dissemination unit within local MH service; PACE: Personal Assessment and Crisis Evaluation clinic (Melbourne, Australia); PAS: Psychological Assistance Service (Newcastle, Australia); SD: Standard deviation; SPSS: Statistical Package for Social Sciences; UHR: Ultra High Risk (for psychosis).}

\section{Competing interests}

The authors declare that they have no competing interests.

\section{Authors' contributions}

AMC drafted the manuscript and contributed to project design, data collection, management, analysis and interpretation; TJL and VJC initiated the project and contributed to project design, statistical analysis and interpretation, and manuscript revision; KAS contributed to project design, data collection, management and analysis, and manuscript revision; US, SAH and $\mathrm{MH}$ were additional project investigators who contributed primarily to project design, clinical interpretation of the data, and revision of the manuscript. All authors read and approved the final manuscript.

\section{Acknowledgements}

We wish to thank the staff and clients of the participating $\mathrm{MH}$ services, together with HNE staff who supported data access and extraction (Dinesh Arya, Vanessa Clark, Tony Druce, Kevin Fletcher, Erika Giegerl, Gemma Howard, Judy Kennedy, Anthony Landers, Chris Lowe, Kathy Mason, and Robin Parker). This project received some funding from the Australian Rotary Health Research Fund. Internal support was also provided by the MH-READ unit within HNE MH services. US and VJC were supported by the National Health and Medical Research Council (Project Grant \#569295: Neurocognitive correlates of transition from ultra-high risk mental state to schizophrenia) and the Schizophrenia Research Institute, utilising infrastructure funding from the NSW Ministry of Health, and NSW Trade and Investment.

\section{Author details}

${ }^{1} \mathrm{CTNMH}$ (MH-READ), Hunter New England Mental Health and the University of Newcastle, McAuley Centre, The Mater, PO Box 833, Newcastle NSW 2300, Australia. 'Schizophrenia Research Institute, Darlinghurst, Sydney NSW 2010, Australia. ${ }^{3}$ School of Psychiatry, University of New South Wales, Kensington NSW 2033, Australia. ${ }^{4}$ Psychological Assistance Service, Hunter New England Mental Health, Newcastle NSW 2300, Australia. ${ }^{5}$ School of Psychology,

University of Newcastle, Callaghan NSW 2308, Australia.

Received: 10 March 2014 Accepted: 24 October 2014

Published online: 18 November 2014

\section{References}

1. Yung AR, McGorry PD: The initial prodrome in psychosis: descriptive and qualitative qspects. Aust N Z J Psychiatry 1996, 30:587-599. 
2. Yung AR, Phillips $L$, Yuen HP, Francey $S M$, McFarlane $C A$, Hallgren $M$, McGorry PD: Psychosis prediction: 12-month follow up of a high-risk ("prodromal") group. Schizophr Res 2003, 60:21-32.

3. Yung AR, Nelson B, Stanford C, Simmons MB, Cosgrave EM, Killackey E, Phillips LJ, Bechdolf A, Buckby J, McGorry PD: Validation of "prodromal" criteria to detect individuals at ultra high risk of psychosis: 2 year follow-up. Schizophr Res 2008, 105:10-17.

4. Yung AR, Nelson B, Thompson A, Wood SJ: The psychosis threshold in Ultra High Risk (prodromal) research: is it valid? Schizophr Res 2010, 120:1-6.

5. Yung AR: Risk, disorder and diagnosis. Aust N Z J Psychiatry 2011, 45:915-919.

6. Fusar-Poli P, Borgwardt S, Bechdolf A, Addington J, Riecher-Rossler A, Schultze-Lutter F, Keshavan M, Wood S, Ruhrmann S, Seidman $\sqcup$, Valmaggia L, Cannon T, Velthorst E, De Haan L, Cornblatt B, Bonoldi I, Birchwood M, McGlashan T, Carpenter W, McGorry P, Klosterkotter J, McGuire P, Yung A The psychosis high-risk state: a comprehensive state-of-the-art review. JAMA Psychiatry 2013, 70:107-120.

7. Yung AR, Yuen HP, Berger G, Francey S, Hung T-C, Nelson B, Phillips LJ, MCGorry PD: Declining transition rate in ultra high risk (prodromal) services: dilution or reduction of risk? Schizophr Bull 2007, 33:673-681.

8. Correll CU, Hauser M, Auther AM, Cornblatt BA: Research in people with psychosis risk syndrome: a review of the current evidence and future directions. J Child Psychol Psychiatry 2010, 51:390-431.

9. Simon $A E$, Velthorst $E$, Nieman $D H$, Linszen $D$, Umbricht $D$, de Haan L: Ultra high-risk state for psychosis and non-transition: A systematic review. Schizophr Res 2011, 132:8-17.

10. McGorry PD: Pre-emptive intervention in psychosis: Agnostic rather than diagnostic. Aust N Z J Psychiatry 2011, 45:515-519.

11. Jorm AF: 'Prodromal diagnosis' of psychosis: An impartial commentary. Aust N Z J Psychiatry 2011, 45:520-523.

12. Yung AR: Early intervention in psychosis: evidence, evidence gaps, criticism, and confusion. Aust N Z J Psychiatry 2012, 46:7-9.

13. Castle $D$ : The truth, and nothing but the truth, about early intervention in psychosis. Aust N Z J Psychiatry 2012, 46:10-13.

14. McGorry PD: Truth and reality in early intervention. Aust N Z J Psychiatry 2012, 46:313-316.

15. Carr VJ: Time to move on? Commentary on the early intervention in psychosis debate. Aust N Z J Psychiatry 2012, 46:384-385.

16. McGrath JJ: The early intervention debate provides a distraction from another 'unspeakable truth'. Aust N Z J Psychiatry 2012, 46:681-682.

17. Castle D: What, after all, is the truth: Response to McGorry. Aust N Z J Psychiatry 2012, 46:685-687.

18. Jorm AF: Treatment to reduce risk of psychosis: The need to consider the potential harms as well as the benefits. Aust N Z J Psychiatry 2013, 47:881.

19. Ehlkes T, Michie PT, Schall U: Brain imaging correlates of emerging schizophrenia. Neuropsychiatry 2012, 2:147-154.

20. Tanskanen S, Morant N, Hinton M, Lloyd-Evans B, Crosby M, Killaspy H, Raine R, Pilling S, Johnson S: Service user and carer experiences of seeking help for a first episode of psychosis: a UK qualitative study. BMC Psychiatry 2011, 11:157.

21. Preti A, Cella M: Randomized-controlled trials in people at ultra high risk of psychosis: a review of treatment effectiveness. Schizophr Res 2010, 123:30-36.

22. Robinson J, Cotton S, Conus P, Schimmelmann BG, McGorry P, Lambert M: Prevalence and predictors of suicide attempt in an incidence cohort of 661 young people with first-episode psychosis. Aust N Z J Psychiatry 2009, 43:149-157.

23. Lui S: Risk factors for deliberate self-harm and completed suicide in young Chinese people with schizophrenia. Aust N Z J Psychiatry 2009, 43:252-259.

24. Larsen T, Melle I, Auestad B, Haahr U, Joa I, Johannessen J, Opjordsmoen S, Rund B, Rossberg J, Simonsen E, Vaglum P, Friis S, McGlashan T: Early detection of psychosis: positive effects on 5-year outcome. Psychol Med 2011, 41:1461-1469.

25. Connor C, Birchwood M, Palmer C, Channa S, Freemantle N, Lester H, Patterson $\mathrm{P}$, Singh S: Don't turn your back on the symptoms of psychosis: a proof-of-principle, quasi-experimental public health trial to reduce the duration of untreated psychosis in Birmingham, UK. BMC Psychiatry 2013, 13:67.
26. Marshall M, Lewis $S$, Lockwood A, Drake R, Jones P, Croudace T: Association between duration of untreated psychosis and outcome in cohorts of first-episode patients: a systematic review. Arch Gen Psychiatry 2005, 62:975-983.

27. Malla A, Norman R, Scholten D, Machanda R, Mclean T: A community intervention for the early identification of first episode psychosis impact on duration of untreated psychosis (DUP) and patient characteristics. Soc Psychiatry Psychiatr Epidemiol 2005, 40:337-344.

28. Blanchard JJ, Brown SA, Horan WP, Sherwood AR: Substance use disorders in schizophrenia: Review, integration, and a proposed model. Clin Psychol Rev 2000, 20:207-234.

29. Kavanagh DJ, Waghorn G, Jenner L, Chant DC, Carr V, Evans M, Herrman H, Jablensky A, McGrath JJ: Demographic and clinical correlates of comorbid substance use disorders in psychosis: multivariate analyses from an epidemiological sample. Schizophr Res 2004, 66:115-124.

30. Moore E, Mancuso SG, Slade T, Galletly C, Castle DJ: The impact of alcohol and illicit drugs on people with psychosis: The second Australian national survey of psychosis. Aust N Z J Psychiatry 2012, 46:864-878.

31. Romm KL, Rossberg Jl, Berg AO, Hansen CF, Andreassen OA, Melle I: Assessment of social anxiety in first episode psychosis using the Liebowitz Social Anxiety scale as a self-report measure. Eur Psychiatry 2011, 26:115-121.

32. Yung AR, Phillips LJ, Yuen HP, McGorry PD: Risk factors for psychosis in an ultra high-risk group: psychopathology and clinical features. Schizophr Res 2004, 67:131-142.

33. Velthorst $E_{\text {, Nieman } D H}$, Becker HE, van de Fliert R, Dingemans PM, Klaassen $R$, de Haan L, van Amelsvoort T, Linszen DH: Baseline differences in clinical symptomatology between ultra high risk subjects with and without a transition to psychosis. Schizophr Res 2009, 109:60-65.

34. Addington J, Cornblatt B, Cadenhead K, Cannon T, McGlashan T, Perkins D, Seidman L, Tsuang M, Walker E, Woods S, Heinssen R: At clinical high risk for psychosis: Outcome for nonconverters. Am J Psychiatry 2011, 168:800-805.

35. Varghese D, Scott J, Welham J, Bor W, Najman J, O'Callaghan M, Williams G, McGrath J: Psychotic-like experiences in major depression and anxiety disorders: A population-based survey in young adults. Schizophr Bull 2011, 37:389-393.

36. Häfner H, Maurer K, Trendler G, An der Heiden W, Schmidt M: The early course of schizophrenia and depression. Eur Arch Psychiatry Clin Nuerosci 2005, 255:167-173.

37. Weiser M, van Os J, Davidson M: Time for a shift in focus in schizophrenia: from narrow phenotypes to broad endophenotypes. Br J Psychiatry 2005, 187:203-205.

38. Kotov R, Chang S-W, Fochtmann LJ, Mojtabai R, Carlson GA, Sedler MJ, Bromet EJ: Schizophrenia in the internalizing-externalizing framework: A third dimension? Schizophr Bull 2011, 37:1168-1178.

39. van Nierop M, van Os J, Gunther N, Myin-Germeys I, de Graaf R, ten Have M, van Dorsselaer S, Bak M, van Winkel R: Phenotypically continuous with clinical psychosis, discontinuous in need for care: evidence for an extended psychosis phenotype. Schizophr Bull 2012, 38:231-238

40. Wigman JTW, van Nierop M, Vollebergh WAM, Lieb R, Beesdo-Baum K, Wittchen $\mathrm{H}-\mathrm{U}$, van Os J: Evidence that psychotic symptoms are prevalent in disorders of anxiety and depression, impacting on illness onset, risk, and severity - implications for diagnosis and ultra-high risk research. Schizophr Bull 2012, 38:247-257.

41. Carr V, Halpin S, Lau N, O'Brien S, Beckmann J, Lewin T: A risk factor screening and assessment protocol for schizophrenia and related psychosis. Aust N Z J Psychiatry 2000, 34:S170-S180.

42. Phillips $L$, Yung AR, McGorry PD: Identification of young people at risk of psychosis: validation of Personal Assessment and Crisis Evaluation Clinic intake criteria. Aust N Z J Psychiatry 2000, 34(Suppl):S164-169.

43. Power P, McGuire P, lacoponi E, Garety P, Morris E, Valmaggia L, Grafton D, Craig T: Lambeth Early Onset (LEO) and Outreach \& Support in South London (OASIS) service. Early Interv Psychiatry 2007, 1:97-103.

44. Yung AR, McGorry PD, Francey SM, Nelson B, Baker K, Phillips LJ, Berger G, Amminger GP: PACE: a specialised service for young people at risk of psychotic disorders. Med J Aust 2007, 187:S43-46.

45. Schultze-Lutter F, Ruhrmann S, Klosterkotter J: Early detection of psychosis establishing a service for persons at risk. Eur Psychiatry 2009, 24:1-10. 
46. Meneghelli A, Cocchi A, Preti A: 'Programma2000': a multi-modal pilot programme on early intervention in psychosis underway in Italy since 1999. Early Interv Psychiatry 2010, 4:97-103.

47. Uzenoff SR, Penn DL, Graham KA, Saade S, Smith BB, Perkins DO: Evaluation of a multi-element treatment center for early psychosis in the United States. Soc Psychiatry Psychiatr Epidemiol 2012, 47:1607-1615.

48. Fusar-Poli P, Bonoldi I, Yung AR, Borgwardt S, Kempton MJ, Valmaggia L, Barale F, Caverzasi E, McGuire P: Predicting psychosis: Meta-analysis of transition outcomes in individuals at high clinical risk. Arch Gen Psychiatry 2012, 69:220-229.

49. Phillips $L$, Velakoulis $D$, Pantelis C, Wood S, Yuen HP, Yung AR, Desmond P, Brewer W, McGorry PD: Non-reduction in hippocampal volume is associated with higher risk of psychosis. Schizophr Res 2002, 58:145-158.

50. Cocchi A, Meneghelli A, Erlicher A, Pisano A, Cascio M, Preti A: Patterns of referral in first-episode schizophrenia and ultra high-risk individuals: results from an early intervention program in Italy. Soc Psychiatry Psychiatr Epidemiol 2013, 48:1905-1916.

51. Yung AR, Pan Yuen H, Mcgorry PD, Phillips LJ, Kelly D, Dell'olio M, Francey SM, Cosgrave EM, Killackey E, Stanford C, Godfrey K, Buckby J: Mapping the onset of psychosis: the Comprehensive Assessment of at-Risk Mental States. Aust N ZJ Psychiatry 2005, 39:964-971.

52. National Mental Health Commission (NMHC): A Contributing Life: The 2013 National Report Card on Mental Health and Suicide Prevention. Sydney: NMHC; 2013.

53. Yung AR, Stanford C, Cosgrave E, Killackey E, Phillips L, Nelson B, McGorry PD: Testing the Ultra High Risk (prodromal) criteria for the prediction of psychosis in a clinical sample of young people. Schizophr Res 2006, 84:57-66.

54. Rickwood DJ, Telford NR, Parker AG, Tanti CJ, McGorry PD: Headspace Australia's innovation in youth mental health: who are the clients and why are they presenting? Med J Aust 2014, 200:108-111.

doi:10.1186/s12888-014-0318-4

Cite this article as: Conrad et al:: Ten-year audit of clients presenting to a specialised service for young people experiencing or at increased risk for psychosis. BMC Psychiatry 2014 14:318.

\section{Submit your next manuscript to BioMed Central and take full advantage of:}

- Convenient online submission

- Thorough peer review

- No space constraints or color figure charges

- Immediate publication on acceptance

- Inclusion in PubMed, CAS, Scopus and Google Scholar

- Research which is freely available for redistribution 